European Psychiatry

www.cambridge.org/epa

\section{Viewpoint}

Cite this article: Dias MC, Perera B, Riese F, De Picker L, da Costa MP, Petricean A, Kanellopoulos A, Krysta K, Baessler F (2020). Are we training psychiatrists to develop skills in intellectual disability psychiatry? Current European context and future directions. European Psychiatry, 63(1), e99, 1-5 https://doi.org/10.1192/j.eurpsy.2020.102

Received: 12 September 2020 Revised: 02 November 2020 Accepted: 05 November 2020

\section{Keywords:}

Community Mental Health Teams; education and training; intellectual disability; learning disability; specialty training

*Author for correspondence:

Marisa Casanova Dias,

E-mail: casanovadiasm@cardiff.ac.uk (c) The Author(s), 2020. Published by Cambridge University Press on behalf of European Psychiatry Association. This is an Open Access article, distributed under the terms of the Creative Commons Attribution licence (http:// creativecommons.org/licenses/by/4.0/), which permits unrestricted re-use, distribution, and reproduction in any medium, provided the original work is properly cited.

EUROPEAN PSYCHIATRIC ASSOCIATION

\title{
Are we training psychiatrists to develop skills in intellectual disability psychiatry? Current European context and future directions
}

\author{
Marisa Casanova Dias ${ }^{1,2 *}$ (D), Bhathika Perera ${ }^{3}$ (D), Florian Riese $^{4}$ (D), \\ Livia De Picker ${ }^{5,6}$ (D), Mariana Pinto da Costa ${ }^{7,8,9}$, Alina Petricean ${ }^{10}$, \\ Athanasios Kanellopoulos ${ }^{11}$, Krzysztof Krysta ${ }^{12}$ (D) and Franziska Baessler ${ }^{13}$
}

\begin{abstract}
${ }^{1}$ National Centre for Mental Health, School of Medicine, Cardiff University, Cardiff, United Kingdom;
${ }^{2}$ Section of Women's Mental Health, Institute of Psychiatry, Psychology and Neurosciences, King's College London, London, United Kingdom; ${ }^{3}$ Haringey Learning Disability Partnership, Barnet, Enfield and Haringey Mental Health Trust, London, United Kingdom; ${ }^{4}$ Psychiatric University Hospital Zurich, Zurich, Switzerland; ${ }^{5}$ Collaborative Antwerp Psychiatric Research Institute, University of Antwerp, Antwerp, Belgium; ${ }^{6}$ University Psychiatric Hospital Campus Duffel, Antwerp, Belgium; ${ }^{7}$ Unit for Social and Community Psychiatry, WHO Collaborating Centre for Mental Health Services Development, Queen Mary University of London, London, United Kingdom; ${ }^{8}$ Institute of Biomedical Sciences Abel Salazar, University of Porto, Porto, Portugal; ${ }^{9}$ Hospital de Magalhães Lemos, Porto, Portugal; ${ }^{10}$ National Centre for Mental Health, BSMHFT, Birmingham, United Kingdom; ${ }^{11}$ Center for Adolescent Medicine, First Department of Pediatrics, School of Medicine, National and Kapodistrian University of Athens, Aghia Sophia Children's Hospital, Athens, Greece; ${ }^{12}$ Department of Rehabilitation Psychiatry, Medical University of Silesia, Katowice, Poland and ${ }^{13}$ Department of General Internal and Psychosomatic Medicine, Heidelberg University Hospital, Heidelberg, Germany
\end{abstract}

\begin{abstract}
The majority of people with intellectual disabilities (ID) and psychiatric disorders access mainstream mental health services across Europe. However, only 56\% of countries provide postgraduate psychiatric training in ID according to a survey across 42 European countries. We explore the challenges of ID training and make recommendations for education and health policymakers.
\end{abstract}

Intellectual disability (ID) is a neurodevelopmental disorder affecting $1-2 \%$ of the population [1]. Current estimates suggest that there are nearly 7 million people with ID in Europe.

It is well established that people with intellectual disabilities have significantly higher rates of mental [2] and physical health disorders [3] as well as social care needs which must be considered alongside one another. This means that they require high and complex multidisciplinary service provision with an estimated cost of over $€ 43$ billion each year in Europe.

However, the provision of services is often poorly planned and does not necessarily match the needs of people with ID [4-6]. This is not only due to economic constraints, but also due to a more systemic problem of unavailability of community services and skilled professionals. The WHO Atlas on global resources for persons with ID [4] reports that the percentage of countries in Europe reporting specific training in ID for psychiatrists was $46.8 \%$. The other most trained health professionals were: special educators (59.6\%), speech and language therapists (44.7\%), psychologists $(38.3 \%)$, and pediatricians $(21.3 \%)$. It is not surprising that the majority of countries train other health professionals, as much of the work requires a multidisciplinary team. A review of ID training in health sciences across Europe found that studies in this field are scarce in Europe compared with other parts of the world [7]. The only survey done so far that covered postgraduate psychiatry ID training was done in 2004 and only covered 22 countries, out of which only $14(64 \%)$ reported structured ID training [8].

Without qualified and skilled clinicians to look after people with ID, the care and support of people with ID cannot be further improved. Given mental health problems are highly prevalent in people with ID [2], there is a case to re-evaluate current mental health care provisions and skilled staff to manage this group of individuals with multiple vulnerabilities.

\section{The Importance of Postgraduate Psychiatric Education on ID}

Qualified clinicians are an essential pillar to improved care. The content and methods of postgraduate psychiatric training profoundly shape future psychiatrists and the quality of psychiatric care and expertise [9].

In Europe, the international frameworks for training standards, including ID, are issued by the Union Européenne des Médecins Spécialistes (UEMS). Despite these harmonized evidence-based policies, for example "Training Requirements for the specialty of Psychiatry" 
(uemspsychiatry.org), and the automatic mutual recognition of qualification in EU, the practice differs vastly [10].

Each person, regardless of the country they live in, has the right to health, to have the best care possible, and to have it delivered by skilled professionals.

\section{A European Survey of Postgraduate Psychiatry Training Across 42 Countries}

The European Federation of Psychiatric Trainees (EFPT, www.efpt.eu), an umbrella organization for trainee associations, conducted the most comprehensive study so far of postgraduate psychiatric training and provision of ID training across Europe.

In this cross-sectional study, the online questionnaire was sent to the representatives of national psychiatric trainee associations, or trainees with comparable functions and with access to accurate and comprehensive data on national practices in countries without such associations. Topics covered included the general structure and length of psychiatric postgraduate training and specific questions about the availability and provision of ID training.

Out of the 42 countries surveyed in 2014,41 (98\% response rate) answered the questions on the availability of ID training (see Table 1). Twenty-three (56\%) of the countries provided postgraduate psychiatric training on ID and 18 (44\%) did not, of which, one did not have a training scheme of their own. Where training was provided, it took several formats such as lectures, clinical rotations, and case discussions (Table 1). In many countries, ID training was linked to child and adolescent psychiatry training. In two countries, Ireland and the United Kingdom, ID is recognized as a subspecialty with ID training lasting 3 years. This subspecialty training takes place after 3 years of core training in psychiatry (total specialty training of 6 years). In other countries, the length of ID training varied from 6 months, offered as a clinical rotation, to merely hours in those countries offering lectures only. Psychiatry training programs varied considerably in length, from 7 years in Ireland to 1 year in Belarus. In Belarus, despite having the shortest training program, a mandatory 2 -week clinical rotation in "behavioral and emotional disorders with onset usually occurring in childhood and adolescence" is provided.

The design of this study, where the respondents have the responsibility of being national representatives, ensured an extremely high response rate (98\%) and assures us of the accuracy of the data. Furthermore, the information provided reflects the actual experiences of trainees about the provision of training. In countries where training is not nationally standardized there may be bigger variation within different regions of the same country that could not be captured, although these respondents would be the best placed to have such intelligence. The authors are not aware of significant changes to psychiatric training programs since the time of data collection.

To our knowledge, this is the most recent and comprehensive study on this topic. The only other survey done so far that covered postgraduate psychiatry ID training was done in 2004 and was much smaller [8]. It showed that 14 out of the 22 (64\%) countries surveyed offered structured theoretical training in their national training scheme and 5 (23\%) offered mandatory practical training, although it did not specify which countries, so we cannot draw a comparison. That study recommended intellectual disabilities, leadership and management, informatics and telemedicine should be introduced in the training curricula, but we have not seen much progress in over 10 years.

\section{The Outlook of ID Psychiatry in Europe}

\section{Challenges}

The biggest question is whether we need specialists in ID psychiatry.

In many countries, less time available for training and constraints of service provision during training limit the exposure to ID. Limited exposure to people with ID and their problems contributes to increase the stigma these people already face. Previous exposure, either in personal or working life, has shown to influence choice of ID subspecialty training. Different modalities of training operate in Europe with a debate about the need for a subspecialty in ID versus the need for all psychiatrists to have ID training. The former has been criticized alongside other subspecialties as it can lead to fragmentation of care. The latter, despite great efforts, has yet to be implemented within and between countries.

The cost of ignorance on the subject matter due to lack of training can be far-reaching. Firstly, diagnosing mental disorders in people with ID can be challenging for many reasons. There is the risk of under-diagnosing or mis-diagnosing mental disorders in people with ID. The presence of multiple physical, neurodevelopmental, and psychiatric co-morbidities can change the way mental illnesses present in people with ID. Diagnostic overshadowing is very commonly reported. Lower intellectual functioning along with communication difficulties can affect how psychiatric symptoms are manifested. Failing to identify and treat early can have an adverse outcome in health leading to premature death and social disintegration. Secondly, lack of skills to identify the real issues and lack of knowledge or availability of specialist multidisciplinary centers lead to unwarranted and off-label prescription of medication, for example, antipsychotics with the deleterious consequences associated with those, or to over-use of physical restraint. Thirdly, the lack of skilled adult psychiatrists leads on many occasions to child and adolescent psychiatrists being approached by parents of people with ID already in their 20s because they are desperate and have no-one to turn to with sufficient expertise.

\section{Recommendations for education and health policymakers}

- Given the above, the authors believe ID psychiatry should be a mandatory part of training curricula and exams (assessment drives learning) in all European countries.

- Weacknowledge the different challenges faced by different countries, related to economic power, organization of services, organization of training, provision of social care, and general societal expectations. Nonetheless, we suggest that through harmonized training-between and within countries-we can promote harmonized care despite all the existing contextual differences [10].

- Professional exchange programs, like those provided by EFPT and EPA offer a means to complement the training curricula where opportunities are not available locally.

- Importantly, even after the completion of postgraduate training, the provision of quality Continuous Medical Education (CME) on the topic, especially through new technologies, can increase the reach of ID training, overcoming location and economic barriers.

- We recommend that ID training should not be limited to CAP training, but should work on facilitating the transition between CAP, when the disorders are normally identified, adult psychiatry, as well as old age psychiatry-as the life-expectancy of people with ID continues to increase. 
Table 1. Intellectual Disability Psychiatry training offered across 42 European countries

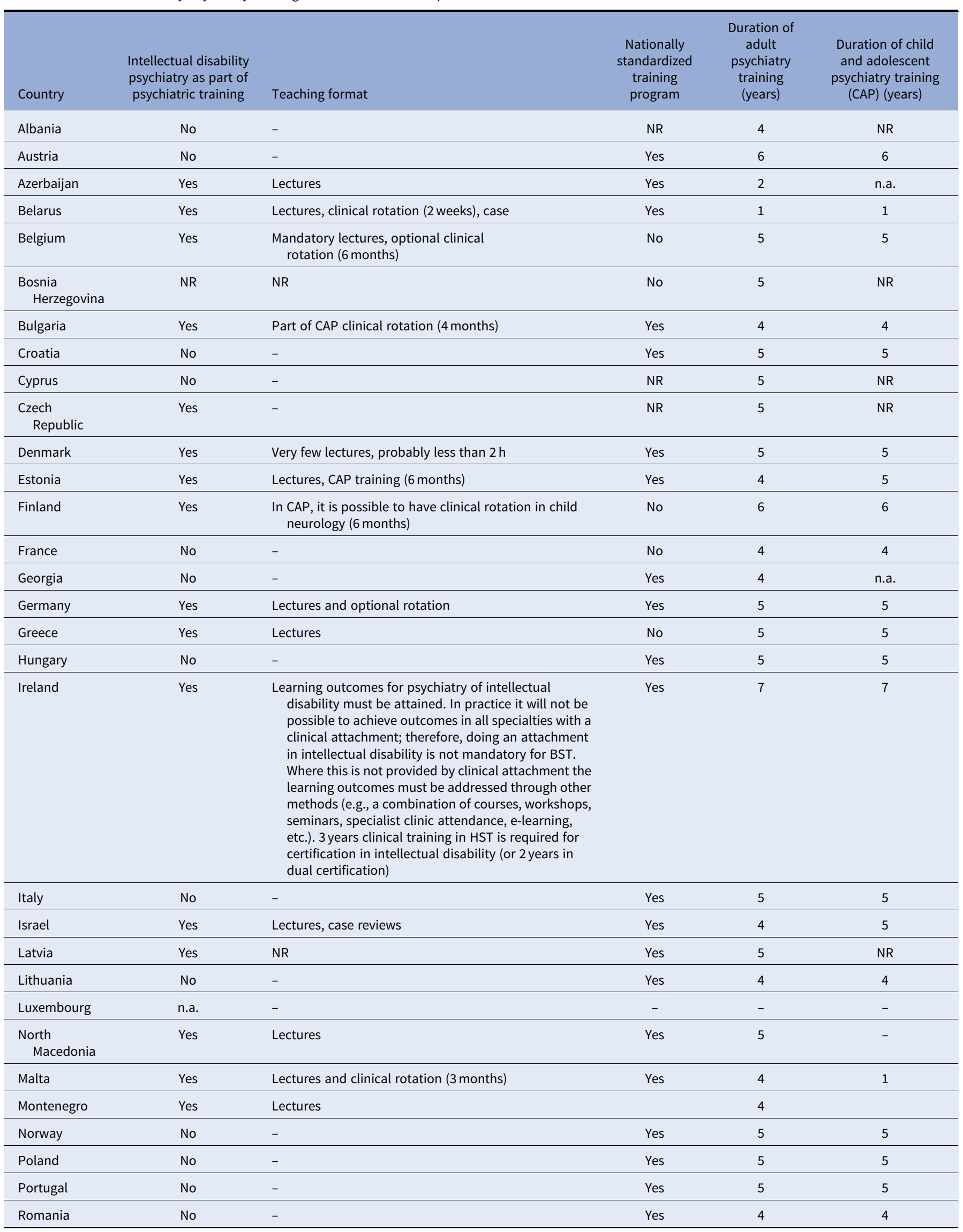


Table 1. Continued

\begin{tabular}{|c|c|c|c|c|c|}
\hline Country & $\begin{array}{l}\text { Intellectual disability } \\
\text { psychiatry as part of } \\
\text { psychiatric training }\end{array}$ & Teaching format & $\begin{array}{l}\text { Nationally } \\
\text { standardized } \\
\text { training } \\
\text { program }\end{array}$ & $\begin{array}{l}\text { Duration of } \\
\text { adult } \\
\text { psychiatry } \\
\text { training } \\
\text { (years) }\end{array}$ & $\begin{array}{l}\text { Duration of child } \\
\text { and adolescent } \\
\text { psychiatry training } \\
\text { (CAP) (years) }\end{array}$ \\
\hline Russia & Yes & $\begin{array}{l}\text { Lectures, examinations (mandatory), rotations } \\
\text { (optional) }\end{array}$ & Yes & 2 & n.a. \\
\hline Serbia & Yes & Lectures and clinical practice & Yes & 4 & 4 \\
\hline Slovakia & No & - & Yes & 5 & 5 \\
\hline Slovenia & No & - & Yes & 5 & 5 \\
\hline Spain & Yes & - & NR & 4 & n.a. \\
\hline Sweden & Yes & Lectures and clinical rotation & Yes & 5 & 5 \\
\hline Switzerland & No & - & Yes & 6 & 6 \\
\hline $\begin{array}{l}\text { The } \\
\text { Netherlands }\end{array}$ & No & - & Yes & 5 & 3 \\
\hline Turkey & Yes & Lectures, outpatient practice, forensic psychiatry & Yes & 4 & 4 \\
\hline Ukraine & Yes & Lectures & Yes & 1 & 2 \\
\hline $\begin{array}{l}\text { United } \\
\text { Kingdom }\end{array}$ & Yes & $\begin{array}{l}\text { This is taught as part of the compulsory MRCPsych exam } \\
\text { preparation course and is tested in the exam. } \\
\text { Additionally, some trainees may complete an ID } \\
\text { placement ( } 6 \text { months) during core training. There is } \\
\text { also the possibility of completing the 3-year higher } \\
\text { specialty training program in ID. }\end{array}$ & Yes & 6 & 6 \\
\hline
\end{tabular}

This information is correct at the time of collection (2014-2015). The authors are not aware of significant changes to psychiatric training programs since then. The information provided reflects the actual experiences of trainees about the provision of training. In countries where training is not nationally standardized, there may be bigger variation within different regions of the same country. There is no psychiatric training program in Luxembourg.

Abbreviations: n.a., not applicable; NR, no response; BST, Basic Specialist Training; HST, Higher Specialist Training; MRCPsych, Membership of the Royal College of Psychiatrists.

- Last but not least, it is important to remember that improvements in the field will come from good cooperation with other professionals and including people with ID, their families, and carers as stakeholders.

National and international policy is an important lever for directing and effecting change. Without improvements in postgraduate psychiatric training in ID, psychiatric care for people with ID will not fundamentally improve. Looking at the survey results, not much has happened in the past decade. For the benefit of people with ID, we need to come together to make a more active push for curriculum reform across Europe.

Supplementary Materials. To view supplementary material for this article, please visit http://dx.doi.org/10.1192/j.eurpsy.2020.102

Financial Support. This research received no specific grant from any funding agency, commercial or not-for-profit sectors. FB research was supported by the Olympia Morata Program of the Medical Faculty Heidelberg University.

Conflicts of Interest. M.C.D. was the president of EFPT when the data was collected is currently vice-president for CME at UEMS. F.R., L.D.P., M.P.C., A.P., A.K., and F.B. were all board EFPT board members at the time. BP is secretary of the Mental Health and Intellectual Disabilities section at EPA and K.K. is the chair. M.P.C. is chair of the Early Career Psychiatrist Committee at EPA and L.D.P. is member of the EPA Committee on Education.

F.B. reports grants form Medical Faculty Heidelberg University. B.P. reports personal fees from Flynn Pharma, outside the submitted work. L.D.P. reports scientific involvement with Boehringer-Ingelheim, outside the submitted work. F.R. reports personal fees from Merz Pharma and personal fees from Vifor Pharma, outside the submitted work.
Authorship Contributions. M.C.D. designed the questions on ID training to be included in the questionnaire. M.C.D., F.R., M.P.C., L.D.P., F.B., A.K., and A.P. reviewed all the questions to be included in the EFPT 2014 questionnaire, from which the data presented in this editorial was selected. F.B. collected data from European countries without a trainee association. M.C.D. and B.P. conceptualized this editorial. M.C.D. wrote the first draft. B.P. and K.K. contributed to discussion about ID. L.D.P. created the map. All authors contributed to the writing and approved the final version.

Data Availability Statement. The data that support the findings of this study are available from the corresponding author, M.C.D., upon reasonable request.

Ethical Statement. There was no direct patient involvement in this study.

Acknowledgments. We would like to thank the European Federation of Psychiatric Trainees (EFPT) and its former board members who throughout the years iteratively designed the annual survey questionnaire on general aspects of postgraduate psychiatric training. We would also like to thank country representatives from the EFPT and from the countries where there is not a national trainee association who contributed with information. We would like to thank those involved in the discussions around general aspects of psychiatric training which formed part of FB Master's thesis [Structure of Psychiatric Training in 41 countries].

\section{References}

1. Maulik PK, Mascarenhas MN, Mathers CD, Dua T, Saxena S. Prevalence of intellectual disability: a meta-analysis of population-based studies. Res Dev Disabil. 2011;32:419-36.

2. Cooper S, Smiley E, Morrison J, Williamson A, Williamson AW, Allan L. Mental ill-health in adults with intellectual disabilities: prevalence and associated factors. Br J Psychiatry. 2007;190:27-35. 
3. Perera B, Audi S, Solomou S, Courtenay K, Ramsay H. Mental and physical health conditions in people with intellectual disabilities: comparing local and national data. Br J Learn Disabil. 2020;48(1):19-27.

4. World Health Organization. Atlas: global resources for persons with intellectual disabilities: 2007. Geneva: World Health Organization, 2007.

5. World Health Organization. Regional Office for Europe. Mental health, human rights and standards of care. Assessment of the quality of institutional care for adults with psychosocial and intellectual disabilities in the WHO European Region. Copenhagen: WHO Regional Office for Europe, 2018.

6. Hassiotis A, Guinn A, Tanzarella M, McCarthy J, Roy A. Community-based services for people with intellectual disability and mental health problems Literature review and survey results. Faculty of Psychiatry of Intellectual Disability, The Royal College of Psychiatrists 2015.
7. Salvador-Carulla L, Martínez-Leal R, Heyler C, Alvarez-Galvez J, Veenstra MY, García-Ibáñez J, et al. Training on intellectual disability in health sciences: the European perspective. Int J Dev Disabil. 2015;61(1):20-31.

8. Lotz-Rambaldi W, Schäfer I, ten Doesschate R, Hohagen F. Specialist training in psychiatry in Europe-results of the UEMS-survey. Eur Psychiatry. 2008;23(3):157-68.

9. Casanova Dias M, Riese F, Tasman A. Curriculum development for psychiatric training. In: Fiorillo A, Volpe U, Bhugra D, editors. Psychiatry in practice: education, experience and expertise. Oxford: Oxford University Press; 2016.

10. Baessler F, Riese F, Pinto Da Costa M, De Picker L, Kazakova O, Kanellopoulos A, et al. Becoming a psychiatrist in Europe: The title is recognized across the European Union, but what are the differences in training, salary and working hours? Vol 14. World Psychiatry, 2015;p. 372-3. 